ARTICLE

Received 11 Feb 2015 | Accepted 1 Jun 2015 | Published 2 Jul $2015 \quad$ DOl: 10.1038/ncomms8674 $\quad$ OPEN

\title{
Identification of Alp1U and Lom6 as epoxy hydrolases and implications for kinamycin and lomaiviticin biosynthesis
}

Bin Wang ${ }^{1,2, *}$, Fang Guo ${ }^{1,2, \star}$, Jinwei Ren ${ }^{3}$, Guomin $\mathrm{Ai}^{1}$, Bertrand Aigle ${ }^{4,5}$, Keqiang Fan ${ }^{1} \&$ Keqian Yang ${ }^{1}$

The naturally occurring diazobenzofluorenes, kinamycins, fluostatins and lomaiviticins, possess highly oxygenated A-rings, via which the last forms a dimeric pharmacophore. However, neither the A-ring transformation nor the dimerization mechanisms have been explored thus far. Here we propose a unified biosynthetic logic for the three types of antibiotics and verify one key reaction via detailed genetic and enzymatic experiments. Alp1U and Lom6 from the kinamycin and lomaiviticin biosynthesis, respectively, are shown to catalyse epoxy hydrolysis on a substrate that is obtained by chemical deacetylation of a kinamycin-pathway-derived intermediate. Thus, our study provides the first evidence for the existence of an epoxy intermediate in lomaiviticin biosynthesis. Furthermore, our results suggest that the dimerization in the lomaiviticin biosynthesis proceeds after dehydration of a product generated by Lom6.

\footnotetext{
${ }^{1}$ State Key Laboratory of Microbial Resources, Institute of Microbiology, Chinese Academy of Sciences, Beijing 100101, China. ${ }^{2}$ College of Life Sciences, University of Chinese Academy of Sciences, Beijing 100049, China. ${ }^{3}$ State Key Laboratory of Mycology, Institute of Microbiology, Chinese Academy of Sciences, Beijing 100101, China. ${ }^{4}$ Université de Lorraine, Dynamique des Génomes et Adaptation Microbienne, UMR 1128, Vandœuvre-lès-Nancy F-54506, France. ${ }^{5}$ INRA, Dynamique des Génomes et Adaptation Microbienne, UMR 1128, Vandœuvre-lès-Nancy F-54506, France. * These authors contributed equally to this work. Correspondence and requests for materials should be addressed to K.F. (email: fankq@im.ac.cn) or to K.Y. (email: yangkq@im.ac.cn).
} 
A ntibiotics of the kinamycin class, including the kinamycins $^{1}$, fluostatins ${ }^{2,3}$ and lomaiviticins ${ }^{4,5}$, possess three unique functionalities generated in one assembly line, that is, the benzofluorene core, the diazo group and the highly oxygenated A-ring; all three functionalities were reported to be potentially connected to their novel antibiotic and antitumour activities ${ }^{6-10}$. Recently, lomaiviticins attracted renewed interest due to their dimeric structure joined by a $\mathrm{C}-\mathrm{C}$ bond between kinamycin-like monomers. Also because among lomaiviticins, lomaiviticin A was demonstrated to exhibit potent cytotoxicity at $\mathrm{nM}-\mathrm{pM}$ concentrations ${ }^{11}$. The biosynthetic machineries forming the benzofluorene core and diazo group were proposed to be shared by all three pathways, and formation of the benzofluorene in the alp cluster (for the kinamycin biosynthesis) has recently been elucidated by our group ${ }^{12}$. The highly oxygenated A-rings, however, reflect their evolutionary divergence, that is, a four-oxygen-substituted (tetra-hydroxyl) A-ring in kinamycins and three-oxygensubstituted A-rings in fluostatins and lomaiviticins, which undergo further modifications such as acylation, glycosylation or dimerization.

From careful inspection of the diverse structures of the kinamycins and fluostatins, combined with our present results, we propose a unified biosynthetic logic for construction of the oxygen-substituted A-rings, and propose candidate enzymes (Fig. 1). To verify our hypothesis in the kinamycin and lomaiviticin pathways, we focused on one key enzyme, the epoxy hydrolase, whose product not only could confirm the existence of an epoxy intermediate and an epoxidase accordingly but also shed light on the dimerization precursor. We extended the previously proposed incomplete alp cluster ${ }^{13,14}$ in Streptomyces ambofaciens to the far side of the genome to include region 1 and proved that an epoxy hydrolase, Alp1U, is responsible for the epoxy opening on epoxykinamycin (1) via detailed genetic and enzymatic analyses. Lom6, as the predicted counterpart of Alp1U in the lomaiviticin biosynthesis, was subsequently analysed and proved to work on 1, suggesting that a monomeric epoxy intermediate also exists in the lomaiviticin biosynthesis and undergoes a similar epoxy opening process as predicted. The results presented here allow us to revise previous predictions for the lomaiviticin A-ring transformation, and facilitate future investigation of the dimerization reaction.

\section{Results}

Extension of the alp gene cluster. We noted that the previously predicted alp cluster ${ }^{14}$ is incomplete, not only for lacking the genes of the diazo assembly machinery but also for genes involved in the A-ring transformation. As predicted by Gould ${ }^{15,16}$, the kinamycin A-ring transformation from prekinamycin to ketoanhydrokinamycin proceeds similarly to the biosynthesis of antibiotic LLC10037a (Supplementary Fig. 1). Thus, at least two oxygenases or an additional reductase is required. We further hypothesized that an epoxy hydrolase should be necessary to generate the tetra-hydroxyl kinamycin $\mathrm{F}(2)$. However, all oxygenases in the previously proposed alp cluster have already been assigned functions. Consequently, we extended the alp cluster to include region 1 (SAMT0157-0134) via comparative bioinformatic analysis (Supplementary Fig. 2 and Supplementary Table 1). Region 1 was further divided into five subregions, among which the subregion from alp $1 \mathrm{~A}$ to alp $1 \mathrm{H}$ is speculated to be involved in the detoxification reactions
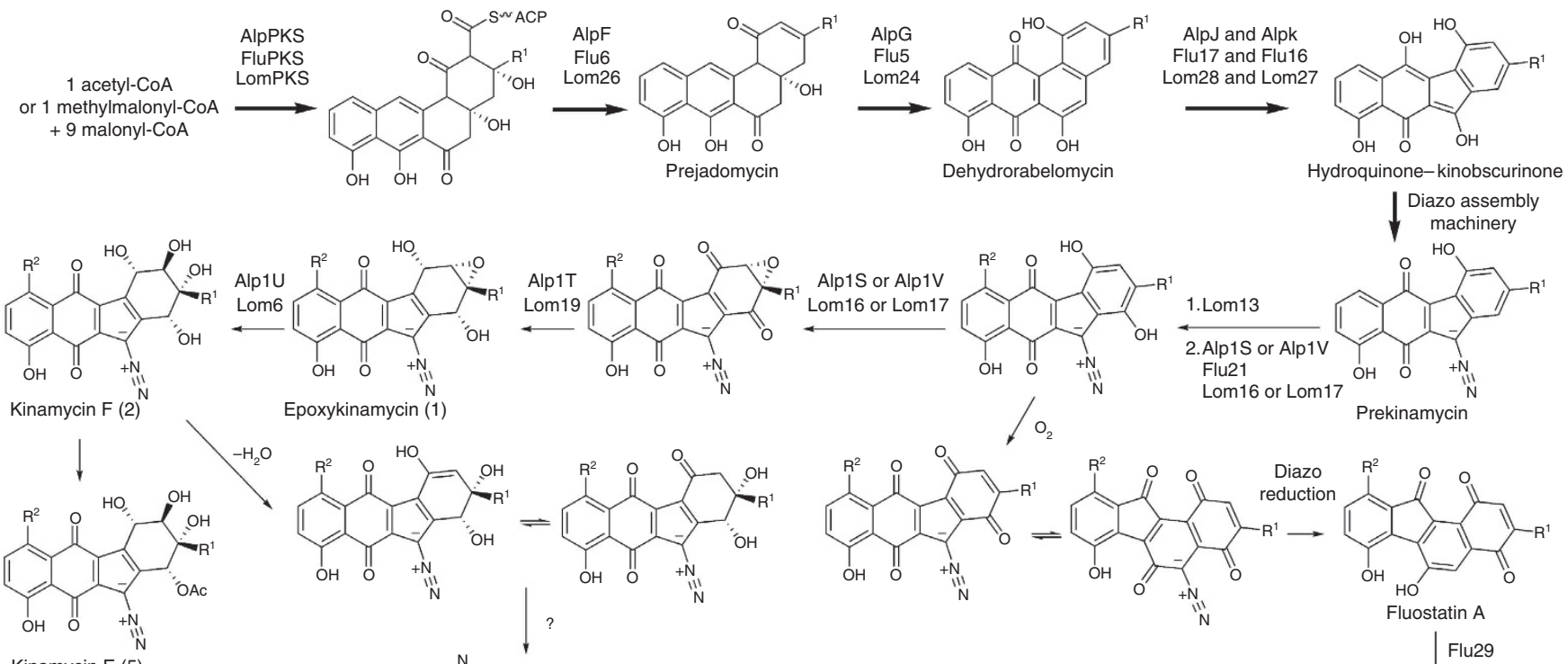

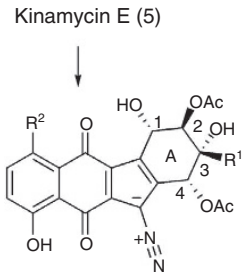

Kinamycin D (3)

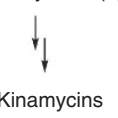

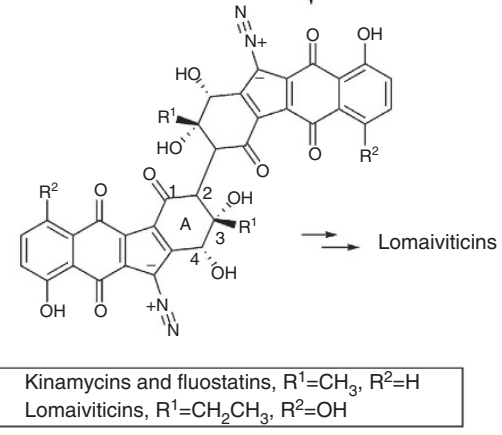
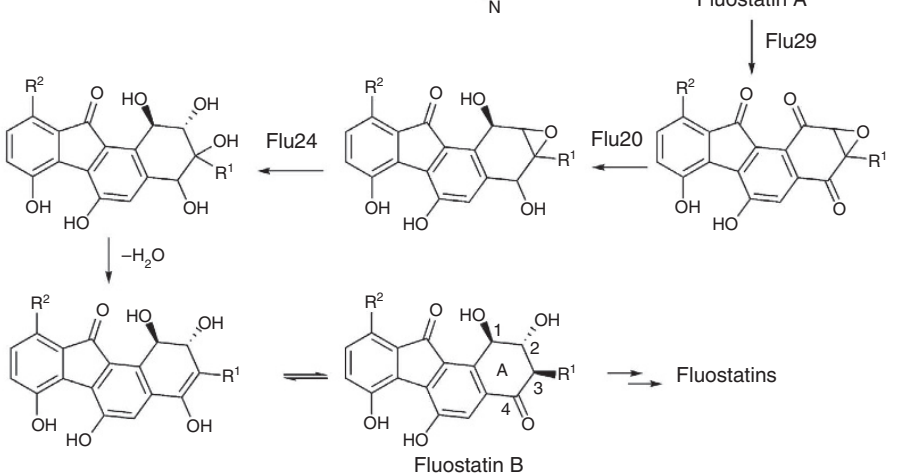

Figure 1 | The proposed biosynthetic pathway for kinamycin class antibiotics. 
(activating the mycothiol biosynthetic pathway to $S$-conjugate the toxic intermediates) ${ }^{17}$ and DNA damage-repair pathways; the subregion from alp $1 I$ to alp $1 N$ is highly conserved among the alp, $f l u$ and lom clusters (Supplementary Fig. 2), thus it is proposed to be involved in the diazo assembly; the subregion from alp1O to alp $1 R$ is mainly composed of transporters; and the subregion from alp $1 S$ to alp $1 V$ is a seemingly independent subset of four genes whose annotations suggest they encode enzymes for kinamycin A-ring transformation; and the subregion including alp $1 W$ and alp $1 X$ is predicted to be involved in diazo formation as well.

Phylogenetic analysis of the oxygenases in the alp, flu and lom gene clusters demonstrates that the enzymes predicted to be involved in the A-ring transformation (Alp1S and Alp1V, Flu21 and Flu29, and Lom16 and Lom17, respectively) with the exception of Flu29 are clustered in a branch distinct from those well-characterized oxygenases involved in biosynthesis of angucycline antibiotics, suggesting that these oxygenases (represented by Alp1S and Alp1V) catalyse similar A-ring transformation reactions, that is, a C4-hydroxylation and a C2, C3-epoxidation, and that Flu29 is probably the epoxidase working on an isomerized fluostatin intermediate (Supplementary Fig. 3). In addition, a substrate-based clustering is also observed by the neighbour joining of enzymes from the same gene clusters (Alp1S with Alp1V, and Lom16 with Lom17). Stand-alone BLAST was then performed to re-analyze all proteins coded by the three gene clusters to identify the counterparts of Alp1T and Alp1U. Combined with visual inspection of the conserved domain(s), Flu20 and Flu24, and Lom6 and Lom19, were putatively assigned.

The next step is predicted to be a C1-, C4-keto reduction catalysed by short-chain dehydrogenase/reductase (SDR) family proteins. Sequence alignment shows that the three NDP-dependent epimerases, Alp1T, Flu20 and Lom19, share a common SDR domain but display rather low identities $(\sim 30 \%$, enzymes of the SDR superfamily typically show low sequence identity in the $15-30 \%$ range $^{18}$ ). Lom 19 was recently predicted to be the dimerization enzyme, based on similarity to ActVA-orf4 (refs 4,5), but evidence for this is still lacking.

The structure diversity of A-rings of the kinamycins and fluostatins led us to hypothesize the existence of an epoxy A-ring intermediate in the lomaiviticin biosynthetic pathway, and accordingly an epoxidase and an epoxy hydrolase. A conserved domain search demonstrates that Alp1U, Flu24 and Lom6 all belong to the $\alpha / \beta$-hydrolase family, but the pairwise sequence alignment shows that Flu24 and Lom6 display high similarity (62\%) but differ remarkably from Alp1U (28 and 25\% similarity, respectively), which is consistent with our prediction that an epoxy hydrolysis reaction on the A-ring of fluostatins and lomaiviticins should be followed by a dehydration reaction, resulting in the mono-hydroxyl group at $\mathrm{C} 2$ and $\mathrm{C} 3$, respectively, rather than the di-hydroxyl found on kinamycins. Accordingly, the C4-keto in fluostatins and C1-keto in lomaiviticins could be explained by keto-enol tautomerization following epoxy

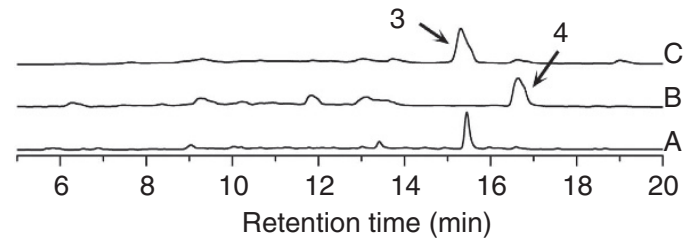

Figure 2 | HPLC profiles of crude extracts from mutants studied in this work. Trace $A$, the starting strain producing kinamycin $D(\mathbf{3})$; trace $B$, $\Delta \Delta$ alp $1 \mathrm{U}$ producing epoxykinamycin $\mathrm{FL}-120 \mathrm{~B}^{\prime}(\mathbf{4})$; trace $\mathrm{C}, \Delta \Delta$ alp $1 \mathrm{U}::$ alp $1 \mathrm{U}$ restoring the production of $\mathbf{3}$. hydrolysis and dehydration. These reactions would generate the dimerization precursor in the lomaiviticin biosynthesis, which would then be dimerized by an as yet unidentified phenol-coupling oxidase ${ }^{19,20}$.

Functional analysis of Alp1U. Since the alp cluster (including region 1) is located in the chromosomal terminal inverted repeats in S. ambofaciens ${ }^{13,14}$, both copies of alp $1 U$ were first in-frame deleted to investigate the function of the epoxy hydrolases (Supplementary Fig. 4). The mutant, $\Delta \Delta a l p 1 U$, was unable to produce kinamycin D (3), but accumulated a yellow compound (4) instead (Fig. 2). Liquid chromatography-mass spectrometry (LC-MS) analysis suggested it to be epoxykinamycin FL-120B' $\left(\mathrm{m} / z 393[\mathrm{M}-\mathrm{H}]^{-}\right)$, which is a known compound previously isolated from Streptomyces chattanoogensis ${ }^{21}$ and also detectable in trace quantities in our starting strain ${ }^{13}$. After large-scale fermentation and purification, ${ }^{1} \mathrm{H},{ }^{13} \mathrm{C}$ NMR data of $\mathbf{4}$ were collected and compared with the previously reported data ${ }^{21}$. Minor variations in chemical shift were detected, thus we performed NMR again to further collect COSY, QC, HMBC and NOESY data and de novo characterized 4 . In the structure of 4, C2, C3-epoxy A-ring and $\mathrm{O}$-acetylated C4-hydroxyl group were observed. The latter was unexpected according to current predictions $s^{1,4,5}$. The production of $\mathbf{3}$ was restored by introduction of one copy of alp $1 U$ to $\Delta \Delta a l p 1 U$ (Fig. 2), which confirmed that Alp1U functions as epoxy hydrolase in vivo. With 4 in hand as a potential substrate for Alp1U, N-terminal $\mathrm{His}_{6}$-tagged Alp1U was expressed in Escherichia coli and purified to near homogeneity (Supplementary Fig. 5). When $\mathbf{4}$ was incubated with Alp1U, a more hydrophilic compound (5) was produced (Fig. 3). Subsequent LC-MS analysis of $\mathbf{5}$ suggested it to be the predicted intermediate, kinamycin E (Supplementary Fig. 6) ${ }^{1}$. We then performed the reaction on a larger scale to obtain sufficient amount of $\mathbf{5}$ for NMR measurements. Although some difficulties such as solvent selection, compound conversion (Supplementary Fig. 7) and variations in chemical shift were encountered, adequate NMR data could be collected for de novo assignment of 5. NOESY further confirmed the chirality of C2 is the same as kinamycin $\mathrm{E}^{22}$.

Enzymatic analysis of Lom6. Next, to confirm the hypothesis of an epoxy intermediate in the lomaiviticin biosynthesis pathway, we synthesized lom6 and expressed the protein in E. coli (Supplementary Fig. 8). The kinamycin-pathway-derived intermediate 4 was used as substrate to test the activity of Lom6. The same reaction conditions used for Alp1U were applied to Lom6, but high-performance liquid chromatography (HPLC) analysis

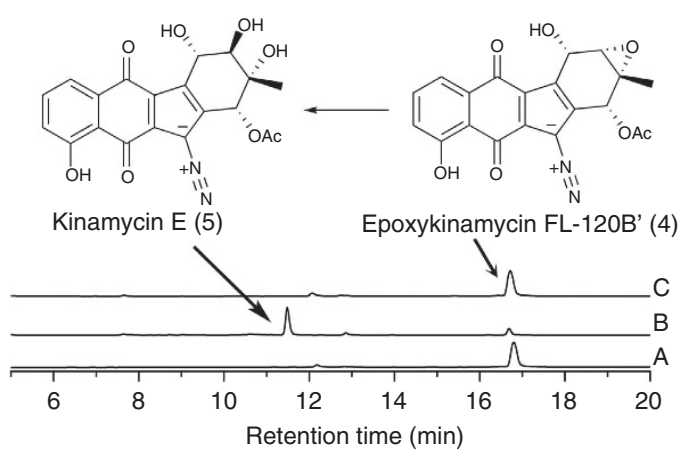

Figure 3 | HPLC analysis of enzymatic reactions. Trace $A$, standard epoxykinamycin $\mathrm{FL}_{-120 \mathrm{~B}^{\prime}}$ (4); trace B, 4 with Alp1U, producing kinamycin E (5); trace C, 4 with Lom6. 
did not provide any evidence for the conversion of 4 by Lom6, even following longer incubation (Fig. 3). This suggests there are structural differences between the structures of $\mathbf{4}$ and the genuine Lom6 substrate. The C4-O-acetyl group is the most conspicuous extra moiety since no acetyl groups was reported on the lomaiviticin antibiotics. Therefore, $\mathbf{1}$ and $\mathbf{2}$ were prepared by alkaline hydrolysis of 4 and 5 (Fig. 4), and confirmed by High Resolution Mass Spectrometry (HRMS). $\mathbf{1}$ is a new compound predicted in Fig. 1 we found to be unstable and degrading within hours. In further tests, 1 could be converted to 2 by Lom6 (Fig. 4), which was confirmed by LC-MS (Supplementary Fig. 9). The same reaction was immediately set for Alp1U, and HPLC analysis indicated that Alp1U converted 1 to 2 (Fig. 4 and Supplementary Fig. 10). These results demonstrate that Lom6 can also act upon 1 as an epoxy hydrolase, but exhibits lower efficiency on the kinamycin-pathway-derived substrate 1 . Incompatibility between 1 and Lom6 might explain those observations, but it is also possible that epoxy hydrolysis catalysed by Lom6 is coupled with dehydration in the lomaiviticin biosynthesis.

\section{Discussion}

The above results clearly demonstrate that Alp1U and Lom6 are epoxy hydrolases. However, it remains surprising that the C4-O-acetylation-which is supposed to occur after epoxy hydrolysis-does not block Alp1U-catalysed epoxy hydrolysis. As previously reported, both $\mathbf{2}$ and $\mathbf{5}$ are confirmed to be intermediates in kinamycin biosynthesis ${ }^{1}$, thus our observation that Alp1U converts both $\mathbf{1}$ to $\mathbf{2}$ and $\mathbf{4}$ to $\mathbf{5}$ implies that $\mathbf{1}$ and $\mathbf{4}$ are intermediates and that the order of the last few steps in the biosynthesis of kinamycin-proximal to the epoxy hydrolysis and $O$-acetylation-are not strictly fixed.

In conclusion, facilitated by comparative bioinformatic analysis we are able to deduce a unified scheme for the A-ring transformation of antibiotics of the kinamycin class (Fig. 1), in which for the first time epoxyquinol intermediates in the kinamycin and lomaiviticin biosynthesis are proposed. We have also demonstrated that Alp1U and Lom6 are epoxy hydrolases that can catalyse the hydrolysis of a kinamycin-pathway-derived epoxy intermediate, suggesting the existence of a similar epoxy intermediate-hence also an epoxidase-in the lomaiviticin pathway. Further work will aim to identify the phenol-coupling oxidase responsible for the dimerization reaction in the lomaiviticin biosynthetic pathway.

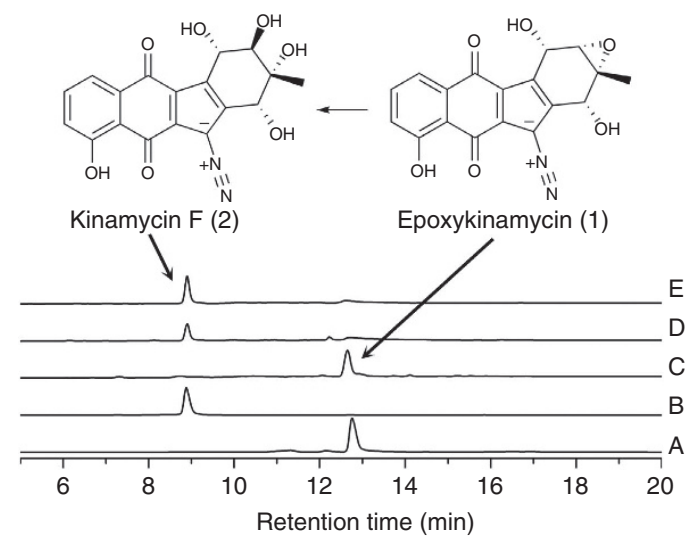

Figure 4 | HPLC traces of enzymatic reactions. Trace $A$, epoxykinamycin $\mathrm{FL}-120 \mathrm{~B}^{\prime}$ (4) treated with $0.1 \mathrm{~N} \mathrm{LiOH}$, forming epoxykinamycin (1); trace $\mathrm{B}$, kinamycin $\mathrm{E}(\mathbf{5})$ treated with $0.1 \mathrm{~N} \mathrm{LiOH}$ forming kinamycin $\mathrm{F}(\mathbf{2})$; trace $\mathrm{C}$, standard 1; trace D, 1 with Lom6 in 50 min producing $\mathbf{2}$; trace $E$, 1 with Alp1U in 10 min producing $\mathbf{2}$

\section{Methods}

General. All cultures of E. coli were grown in Luria-Bertani medium supplemented with appropriate antibiotics at $37^{\circ} \mathrm{C}$. E. coli JM109 was used as host for subcloning, ET12567/pUZ8002 as donor for intergeneric conjugation and BL21(DE3) for protein expression. S. ambofaciens $\Delta \Delta a l p W$ as the starting strain and their derivatives were maintained on MYM solid medium for sporulation, on MS solid medium for conjugation, in R2 liquid medium for metabolite production and in YEME liquid medium for preparing genomic DNA at $28^{\circ} \mathrm{C}$ (ref. 23).

HPLC was carried out on an analytical column Agilent ZORBAX SB-C18 $(4.6 \times 250 \mathrm{~mm}, 5 \mu \mathrm{m})$ connected to a Shimadzu LC-20AT system equipped with a diode array detector monitoring absorbance at 223 and $276 \mathrm{~nm}$. Elution was performed with a linear gradient from 25 to $100 \%$ acetonitrile in water containing $0.1 \%$ trifluoroacetic acid (TFA) for $20 \mathrm{~min}$ at a flow rate of $1.0 \mathrm{ml} \mathrm{min}^{-1}$.

LC-MS was performed on an Agilent 1260/6460 Triple Quadrupole LC/MS system, using an Agilent ZORBAX SB-aq C18 column $(2.1 \times 100 \mathrm{~mm}, 3.5 \mu \mathrm{m})$. High-resolution mass spectrometry measurements were carried out on an Agilent 1200HPLC/6520 Q-TOF-MS mass spectrometer (Agilent Technologies Inc.) within 0.4 p.p.m. errors between theoretical and measured values. All NMR experiments were acquired on a BrukerAvance $500 \mathrm{MHz}\left(B_{0} 11.74 \mathrm{~T}\right)$ spectrometer in $\left(\mathrm{CD}_{3}\right)_{2} \mathrm{SO}$ equipped with a $5 \mathrm{~mm}$ Prodigy probe, using TMS as internal standard.

Bioinformatic analysis was performed, using MEG4.0 Neighbour-Joining method for phylogenetic tree construction, using Stand-alone BLAST (download from http://www.ncbi.nlm.nih.gov/guide/sequence-analysis/) for alignment of the three gene clusters ( $a l p, f l u$ and lom), and using the net-based National Center for Biotechnology Information Conserved Domain Search Service for deduction of protein functions.

Construction of S. ambofaciens $\Delta \Delta$ alp1U. For in-frame deletion of alp1U, two homologous fragments were amplified by PCR from $S$. ambofaciens $\Delta \Delta$ alp $W$ genomic DNA with primers $1 \mathrm{U}$-upF, $1 \mathrm{U}$-upR, $1 \mathrm{U}$-dnF and $1 \mathrm{U}-\mathrm{dnR}$ (sequences and restriction sites in Supplementary Table 4). The PCR products were purified and digested by the corresponding restriction enzymes before ligated to the pre-digested thermal-sensitive plasmid pKC1139, yielding the gene knockout plasmid pKC1139-Dalp1U. The integrity of the insert was confirmed by sequencing at Invitrogen. Then the resulting plasmid was introduced into the starting strain by conjugation from E. coli ET12567/pUZ8002. The transformant were cultured at $28^{\circ} \mathrm{C}$ for two successive generations to enable double-crossover events to occur and then transferred to $37^{\circ} \mathrm{C}$ for plasmid loss. Gene knockout was analysed by PCR using the flanking primers CK-1U-F and CK-1U-R (sequences in Supplementary Table 4).

Complementation of S. ambofaciens $\Delta \mathbf{\Delta a l p 1 U}$. For complementation analysis, the integrative plasmid pSET616, a pSET152 derivative, containing the promoter SF14 and neo reporter gene was used. The alp1U coding sequence plus its ribosome-binding site was PCR amplified using primers $1 \mathrm{U}-\mathrm{F}$ and $1 \mathrm{U}-\mathrm{R}$ (sequences and restriction sites in Supplementary Table 4), and then ligated into the pre-digested pSET616 to create pSET-alp1U. Proper construction of pSET-alp1U was confirmed by DNA sequencing at Invitrogen. The complementation plasmid was then conjugated into $\Delta \Delta$ alp $1 U$ to generate $\Delta \Delta$ alp1U::alp1U. The transformants were cultured at $28^{\circ} \mathrm{C}$ for several successive generations to isolate single colony.

Extraction and preparation of 4. For preparation of 4, a 4-l fermentation broth of the mutant $\Delta \Delta a l p 1 U$ was extracted by ethyl acetate after $\mathrm{pH}$ was adjusted to 3-4. The ethyl acetate was removed by vacuum evaporation, and the extract was dissolved in methanol, and then applied to the Sephadex LH-20 chromatography using methanol as eluting solvent. The fractions containing 4 were collected and pooled, and further purified by reverse-phase semi-preparative HPLC (YMC-Pack Pro $\mathrm{C} 18,250 \times 10 \mathrm{~mm}, 5 \mu \mathrm{m} ; 4 \mathrm{ml} \mathrm{min}^{-1}$, ultraviolet detection at 223 and $276 \mathrm{~nm}$ ) with an isocratic flow of $50 \%$ acetonitrile in water containing $0.1 \%$ TFA. At last, $3.0 \mathrm{mg}$ of 4 was dissolved in $\left(\mathrm{CD}_{3}\right)_{2} \mathrm{SO}$ for NMR measurements (Supplementary Figs 11-16 and Supplementary Table 2).

Epoxykinamycin FL-120B' (4): yellow powder; ${ }^{1} \mathrm{H}$ NMR $\left(\left(\mathrm{CD}_{3}\right)_{2} \mathrm{SO}, 500 \mathrm{MHz}\right)$ $\delta 12.07(1 \mathrm{H}, \mathrm{s}, 7-\mathrm{OH}), 7.72(1 \mathrm{H}, \mathrm{st}, J=7.5 \mathrm{~Hz}, \mathrm{H}-9), 7.63(1 \mathrm{H}, \mathrm{d}, J=7.5 \mathrm{~Hz}, \mathrm{H}-10)$ $7.31(1 \mathrm{H}, \mathrm{d}, J=7.5 \mathrm{~Hz}, \mathrm{H}-8), 6.34(1 \mathrm{H}, \mathrm{s}, \mathrm{H}-4), 5.69(1 \mathrm{H}, \mathrm{s}, 3-\mathrm{OH}), 5.06(1 \mathrm{H}, \mathrm{s}$, $\mathrm{H}-1), 3.52(1 \mathrm{H}, \mathrm{s}, \mathrm{H}-2), 2.26\left(3 \mathrm{H}, \mathrm{s}, \mathrm{H}_{3}-14\right), 1.40\left(3 \mathrm{H}, \mathrm{s}, \mathrm{H}_{3}-12\right) ;{ }^{13} \mathrm{C}$ NMR $\left(\left(\mathrm{CD}_{3}\right)_{2} \mathrm{SO}, 125 \mathrm{MHz}\right) \delta 182.8$ (qC, C-6), 180.2 (qC, C-11), 171.0 (qC, C-13), 161.6 (qC, C-7), $137.0(\mathrm{CH}, \mathrm{C}-9),$,134.1 (qC, C-10a), 131.8 (qC, C-11a), 130.2 (qC, C-11b), 129.5 (qC, C-4a), 128.6 (qC, C-5a), 124.9 (CH, C-8), 120.3 (CH, C-10), 115.6 (qC,C-6a), $77.4(\mathrm{CH}, \mathrm{C}-5), 68.8(\mathrm{qC}, \mathrm{C}-4), 63.4(\mathrm{CH}, \mathrm{C}-1), 61.6(\mathrm{CH}, \mathrm{C}-2)$, 58.4 (qC, C-4a), $20.4\left(\mathrm{CH}_{3}, \mathrm{H}_{3}-14\right), 19.39\left(\mathrm{CH}_{3}, \mathrm{H}_{3}-12\right)$; HMBC data $\left(\left(\mathrm{CD}_{3}\right)_{2} \mathrm{SO}\right.$, $500 \mathrm{MHz}) \mathrm{H}-1 \rightarrow \mathrm{C}-4 \mathrm{a} ; 1-\mathrm{OH} \rightarrow \mathrm{C}-1, \mathrm{C}-2$; H-2 $\rightarrow$ C-1, C-3, C-11b, C-12; $\mathrm{H}-4 \rightarrow \mathrm{C}-1, \mathrm{C}-3$, C-11b, C-12; 7-OH $\rightarrow$ C-6a, 7, 8; H-8 $\rightarrow$ C-6a, 7, 10; H-9 $\rightarrow$ C-7, $10 \mathrm{a} ; \mathrm{H}-10 \rightarrow \mathrm{C}-6 \mathrm{a}, 8 ; \mathrm{H}_{3}-12 \rightarrow \mathrm{C}-2,3,4 ; \mathrm{H}_{3}-14 \rightarrow \mathrm{C}-13$; NOESY data $\left(\left(\mathrm{CD}_{3}\right)_{2} \mathrm{SO}\right.$, $500 \mathrm{MHz}): \mathrm{H}-1 \leftrightarrow \mathrm{H}-2, \mathrm{H}-4, \mathrm{H}_{3}-12 ; \mathrm{H}-2 \leftrightarrow \mathrm{H}_{3}-12 ; \mathrm{H}-4 \leftrightarrow \mathrm{H}_{3}-12 ; 7-\mathrm{OH} \leftrightarrow \mathrm{H}-8$; $\mathrm{H}-8 \leftrightarrow \mathrm{H}-9 ; \mathrm{H}-9 \leftrightarrow \mathrm{H}-10$. ESIMS $(\mathrm{m} / z):[\mathrm{M}-\mathrm{H}]^{-} 393$.

Protein expression and purification in E. coli BL21(DE3). The alp1U coding sequence was amplified by PCR from $S$. ambofaciens $\Delta \Delta a l p W$ genomic DNA using 
primers Ealp1U-F and Ealp1U-R (sequences and restriction sites in Supplementary Table 4). The lom6 coding sequence was synthesized after codon optimization by Biomed. After digestion with the corresponding restriction enzymes, the DNA fragments were subcloned into pET28a and expressed with an $\mathrm{N}$-terminal $\mathrm{His}_{6}$ fusion tag. The sequences were confirmed by sequencing in Invitrogen. Then the constructs were transformed into E. coli BL21(DE3). Protein expression was induced with $0.1 \mathrm{mM}$ isopropyl- $\beta$-D-thiogalactopyranoside when the cultures were grown at $37^{\circ} \mathrm{C}$ until the $\mathrm{OD}_{600} 0.4-0.6$. And allow the cultures to grow at $20^{\circ} \mathrm{C}$ for an additional $12 \mathrm{~h}$. For protein purification, cells were harvested by centrifugation $(8,000 \mathrm{~g})$ at $4{ }^{\circ} \mathrm{C}$, and resuspended in $1 \times$ binding buffer $(500 \mathrm{mM} \mathrm{NaCl}, 20 \mathrm{mM}$ Tris- $\mathrm{HCl}, 5 \mathrm{mM}$ imidazole, $\mathrm{pH} 7.0$ for Alp1U and $\mathrm{pH} 7.9$ for Lom6). Then cells were disrupted by sonication (total time $10 \mathrm{~min}, 2 \mathrm{~s}$ cooling, $2 \mathrm{~s}$ burst at $250 \mathrm{~W}$ ). Following centrifugation, the supernatant was loaded onto the prewashed Ni-NTA column. The crude proteins were washed firstly with $1 \times$ wash buffer ( $500 \mathrm{mM} \mathrm{NaCl}, 20 \mathrm{mM}$ Tris- $\mathrm{HCl}, 60 \mathrm{mM}$ imidazole, $\mathrm{pH}$ as mentioned above) and then eluted with $0.5 \times$ elute buffer $(500 \mathrm{mM} \mathrm{NaCl}, 20 \mathrm{mM}$ Tris- $\mathrm{HCl}, 500 \mathrm{mM}$ imidazole, $\mathrm{pH}$ as mentioned above). The purified proteins were concentrated by centrifugation $(4,000 \mathrm{~g}, 30 \mathrm{~min})$ in $10 \mathrm{kDa}$ ultrafiltration tubes (Centriplus YM series, Millipore). Protein concentrations were determined by Bradford method ${ }^{24}$ and the purities were assessed by $15 \%$ SDS-PAGE.

In vitro enzyme reactions. All reactions set for Alp1U was performed in $50 \mathrm{mM}$ Tris- $\mathrm{HCl}$ buffer, $\mathrm{pH}$ 7.0, and for Lom6 in buffer $\mathrm{pH}$ 8.0. The enzyme concentrations were $25 \mu \mathrm{M}$ for Alp1U and $\sim 20 \mu \mathrm{M}$ for Lom6. The Alp1U reaction was incubated at $30^{\circ} \mathrm{C}$ for $10 \mathrm{~min}$, and Lom6 reactions varied from 10 to $50 \mathrm{~min}$. Substrates, epoxykinamycin FL-120B' (4) and epoxykinamycin (1), were not quantified but basically of the same quantity in all parallel reactions.

For preparation of kinamycin E (5), the reaction volume was amplified to $200 \mu \mathrm{l}$, incubation time increased to $30 \mathrm{~min}$. Product was extracted by ethyl acetate before purified by semi-preparative column on HPLC. The HPLC gradient was changed to $25-85 \%$ acetonitrile in water containing $0.1 \%$ TFA in $16 \mathrm{~min}$. Finally, $1.0 \mathrm{mg}$ of 5 was dissolved in $\mathrm{CD}_{3} \mathrm{Cl}$ or $\sim 2.0 \mathrm{mg}$ in $\left(\mathrm{CD}_{3}\right)_{2} \mathrm{SO}$ for NMR experiments (Supplementary Figs 17-20 and Supplementary Table 3).

Kinamycin E (5): yellow powder; ${ }^{1} \mathrm{H}$ NMR $\left(\left(\mathrm{CD}_{3}\right)_{2} \mathrm{SO}, 500 \mathrm{MHz}\right) \delta 12.12$ $(1 \mathrm{H}, \mathrm{s}, 7-\mathrm{OH}), 7.70(1 \mathrm{H}, \mathrm{t}, J=8.5 \mathrm{~Hz}, \mathrm{H}-9), 7.61(1 \mathrm{H}, \mathrm{d}, J=8.5 \mathrm{~Hz}, \mathrm{H}-10), 7.29$ $(1 \mathrm{H}, \mathrm{d}, J=8.5 \mathrm{~Hz}, \mathrm{H}-8), 5.76(1 \mathrm{H}, \mathrm{s}, \mathrm{H}-4), 5.26(1 \mathrm{H}, \mathrm{d}, J=6.0 \mathrm{~Hz}, 2-\mathrm{OH}), 5.18$ $(1 \mathrm{H}, \mathrm{d}, J=3.5 \mathrm{~Hz}, 1-\mathrm{OH}), 4.50(1 \mathrm{H}, \mathrm{dd}, J=3.5,6.0 \mathrm{~Hz}, \mathrm{H}-1) 3.87(1 \mathrm{H}, \mathrm{t}, J=6.0 \mathrm{~Hz}$, $\mathrm{H}-2), 2.10\left(3 \mathrm{H}, \mathrm{s}, \mathrm{H}_{3}-14\right), 1.09\left(3 \mathrm{H}, \mathrm{s}, \mathrm{H}_{3}-12\right) ;{ }^{13} \mathrm{C} \mathrm{NMR}\left(\left(\mathrm{CD}_{3}\right)_{2} \mathrm{SO}, 125 \mathrm{MHz}\right)$ $\delta 183.2$ (qC, C-6), 180.2 (qC, C-11), 171.3 (qC, C-13), 161.6 (qC, C-7), $136.9(\mathrm{CH}$, C-9,), 134.3 (qC, C-10a), 132.4 (qC, C-4a), 132.0 (qC, C-11b), 131.4 (qC, C-11a), 128.9 (qC, C-5a), $124.6(\mathrm{CH}, \mathrm{C}-8), 119.9$ (CH, C-10), 115.8 (qC,C-6a), $74.8(\mathrm{CH}$, C-2), 73.2 (qC, C-3), $70.8(\mathrm{CH}, \mathrm{H}-4), 69.3(\mathrm{CH}, \mathrm{H}-1), 21.1\left(\mathrm{CH}_{3}, \mathrm{H}_{3}-14\right), 20.6$ $\left(\mathrm{CH}_{3}, \mathrm{H}_{3}-12\right)$; HMBC data $\left(\left(\mathrm{CD}_{3}\right)_{2} \mathrm{SO}, 500 \mathrm{MHz}\right) \mathrm{H}-1 \rightarrow \mathrm{C}-3,4 \mathrm{a} ; \mathrm{H}-2 \rightarrow \mathrm{C}-1,3$, $11 \mathrm{~b}, 12 ; \mathrm{H}-4 \rightarrow \mathrm{C}-2,5,11 \mathrm{~b}, 12 ; 7-\mathrm{OH} \rightarrow \mathrm{C}-6 \mathrm{a}, 7,8 ; \mathrm{H}-8 \rightarrow \mathrm{C}-6 \mathrm{a}, 7,10 ; \mathrm{H}-9 \rightarrow \mathrm{C}-7$, $10 \mathrm{a} ; \mathrm{H}-10 \rightarrow \mathrm{C}-6 \mathrm{a}, 8 ; \mathrm{H}_{3}-12 \rightarrow \mathrm{C}-2,3,4 ; \mathrm{H}_{3}-14 \rightarrow \mathrm{C}-13$; NOESY data $\left(\left(\mathrm{CD}_{3}\right)_{2} \mathrm{SO}\right.$, $500 \mathrm{MHz}): \mathrm{H}-1 \leftrightarrow \mathrm{H}_{3}-12 ; \mathrm{H}_{3}-12 \leftrightarrow \mathrm{H}-4 ; 7-\mathrm{OH} \leftrightarrow \mathrm{H}-8 ; \mathrm{H}-8 \leftrightarrow \mathrm{H}-9 ; \mathrm{H}-9 \leftrightarrow \mathrm{H}-10$. $\operatorname{ESIMS}(\mathrm{m} / \mathrm{z}):[\mathrm{M}-\mathrm{H}]^{-} 411$.

Preparation of epoxykinamycin (1) and kinamycin F (2). An assay mixture $(50 \mu \mathrm{l})$ composed of substrate 4 or 5 dissolved in $\mathrm{MeOH}$ and $\mathrm{LiOH}(0.1 \mathrm{M})$ was incubated at room temperature for $\sim 5 \mathrm{~min}$. Then the crude product 1 or 2 was desalted using $\mathrm{C} 18$ column and analysed by HPLC. High Resolution Mass Spectrometry (HRMS) $(\mathrm{m} / z)$ : for $\mathbf{1},[\mathrm{M}-\mathrm{H}]^{-}$calcd. for $\mathrm{C}_{18} \mathrm{H}_{11} \mathrm{~N}_{2} \mathrm{O}_{6}, 351.0695$, found 351.0692; for 2, [M-H] ${ }^{-}$calcd. for $\mathrm{C}_{18} \mathrm{H}_{13} \mathrm{~N}_{2} \mathrm{O}_{7}, 369.0801$, found 369.0799.

\section{References}

1. Gould, S. J. Biosynthesis of the kinamycins. Chem. Rev. 97, 2499-2510 (1997).

2. Zhang, W. et al. Fluostatins I-K from the South China Sea-derived Micromonospora rosaria SCSIO N160. J. Nat. Prod. 75, 1937-1943 (2012).

3. Feng, Z., Kim, J. H. \& Brady, S. F. Fluostatins produced by the heterologous expression of a TAR reassembled environmental DNA derived type II PKS gene cluster. J. Am. Chem. Soc. 132, 11902-11903 (2010).

4. Janso, J. E. et al. Discovery of the lomaiviticin biosynthetic gene cluster in Salinispora pacifica. Tetrahedron 70, 4156-4164 (2014).

5. Kersten, R. D. et al. Bioactivity-guided genome mining reveals the lomaiviticin biosynthetic gene cluster in Salinispora tropica. ChemBioChem 14, 955-962 (2013).

6. Colis, L. C. et al. The cytotoxicity of (-)-lomaiviticin A arises from induction of double-strand breaks in DNA. Nat. Chem. 6, 504-510 (2014).

7. Herzon, S. B. \& Woo, C. M. The diazofluorene antitumor antibiotics: structural elucidation, biosynthetic, synthetic, and chemical biological studies. Nat. Prod. Rep. 29, 87-118 (2012).

8. Khdour, O. \& Skibo, E. B. Quinone methide chemistry of prekinamycins: 13C-labeling, spectral global fitting and in vitro studies. Org. Biomol. Chem. 7, 2140-2154 (2009).

9. Feldman, K. S. \& Eastman, K. J. Studies on the mechanism of action of prekinamycin, a member of the diazoparaquinone family of natural products: evidence for both sp2 radical and orthoquinonemethide intermediates. J. Am. Chem. Soc. 128, 12562-12573 (2006).

10. Laufer, R. S. \& Dmitrienko, G. I. Diazo group electrophilicity in kinamycins and lomaiviticin A: potential insights into the molecular mechanism of antibacterial and antitumor activity. J. Am. Chem. Soc. 124, 1854-1855 (2002).

11. Woo, C. M., Ranjan, N., Arya, D. P. \& Herzon, S. B. Analysis of diazofluorene DNA binding and damaging activity: DNA cleavage by a synthetic monomeric diazofluorene. Angew. Chem. Int. Ed. 53, 9325-9328 (2014).

12. Wang, B. et al. Kinamycin biosynthesis employs a conserved pair of oxidases for B-ring contraction. Chem. Commun. (Camb.) 51, 8845-8848 (2015).

13. Bunet, R. et al. Characterization and manipulation of the pathway-specific late regulator AlpW reveals Streptomyces ambofaciens as a new producer of kinamycins. J. Bacteriol. 193, 1142-1153 (2011).

14. Pang, X. et al. Functional angucycline-like antibiotic gene cluster in the terminal inverted repeats of the Streptomyces ambofaciens linear chromosome. Antimicrob. Agents Chemother. 48, 575-588 (2004).

15. Shen, B. \& Gould, S. J. Opposite facial specificity for two hydroquinone epoxidases:(3-si, 4-re)-2, 5-dihydroxyacetanilide epoxidase from Streptomyces LL-C10037 and (3-re, 4-si)-2, 5-dihydroxyacetanilide epoxidase from Streptomyces MPP 3051. Biochemistry 30, 8936-8944 (1991).

16. Gould, S. J. \& Shen, B. Epoxyquinones from 2, 5-dihydroxyacetanilide: opposite facial specificity in the epoxidation by enzymes from Streptomyces LL-C10037 and Streptomyces MPP 3051. J. Am. Chem. Soc. 113, 684-686 (1991).

17. Fahey, R. C. Glutathione analogs in prokaryotes. Biochim. Biophys. Acta 1830, 3182-3198 (2013).

18. Martinez Cuesta, S., Furnham, N., Rahman, S. A., Sillitoe, I. \& Thornton, J. M. The evolution of enzyme function in the isomerases. Curr. Opin. Struct. Biol. 26, 121-130 (2014).

19. Präg, A. et al. Regio- and stereoselective intermolecular oxidative phenol coupling in Streptomyces. J. Am. Chem. Soc. 136, 6195-6198 (2014).

20. Ma, J. et al. Biosynthesis of himastatin: assembly line and characterization of three cytochrome P450 enzymes involved in the post-tailoring oxidative steps. Angew. Chem. Int. Ed. 50, 7797-7802 (2011)

21. Young, J. J., Ho, S. N., Ju, W. M. \& Chang, L. R. FL-120A-D', new products related to kinamycin from Streptomyces chattanoogensis subsp. taitungensis subsp. nov. II. Isolation and structure determination. J. Antibiot. 47, 681-687 (1994).

22. Seaton, P. J. \& Gould, S. J. New products related to kinamycin from Streptomyces murayamaensis. II. Structures of pre-kinamycin, keto-anhydrokinamycin, and kinamycins E and F. J. Antibiot. 42, 189-197 (1989).

23. Kieser, T., Bibb, M. J., Buttner, M. J., Chater, K. F. \& Hopwood, D. A. Practical Streptomyces Genetics (John Innes Foundation Norwich, 2000).

24. Bradford, M. M. A rapid and sensitive method for the quantitation of microgram quantities of protein utilizing the principle of protein-dye binding. Anal. Biochem. 72, 248-254 (1976).

\section{Acknowledgements}

This work was supported by the National Natural Science Foundation of China (Grant 31470176 and 31130001) and the Ministry of Science and Technology of China (Grant 2013CB734001).

\section{Author contributions}

K.Y., K.F., B.W. and F.G. designed experiments; F.G., B.W., J.R. and G.A. conducted all the in vivo and in vitro experiments; B.W., F.G., J.R., B.A. and K.Y. wrote the paper.

\section{Additional information}

Supplementary Information accompanies this paper at http://www.nature.com/ naturecommunications

Competing financial interests: The authors declare no competing financial interests.

Reprints and permission information is available online at http://npg.nature.com/ reprintsandpermissions/

How to cite this article: Wang, B. et al. Identification of Alp1U and Lom6 as epoxy hydrolases and implications for kinamycin and lomaiviticin biosynthesis. Nat. Commun. 6:7674 doi: 10.1038/ncomms8674 (2015).

\section{(i)}

This work is licensed under a Creative Commons Attribution 4.0 International License. The images or other third party material in this article are included in the article's Creative Commons license, unless indicated otherwise in the credit line; if the material is not included under the Creative Commons license, users will need to obtain permission from the license holder to reproduce the material To view a copy of this license, visit http://creativecommons.org/licenses/by/4.0/ 